Article

\title{
Eco-Structured Biosorptive Removal of Basic Fuchsin Using Pistachio Nutshells: A Definitive Screening Design-Based Approach
}

\author{
Marwa El-Azazy* ${ }^{(\mathbb{D}}$, Ahmed S. El-Shafie ${ }^{\circledR}$, Aya Ashraf and Ahmed A. Issa \\ Department of Chemistry and Earth Sciences, College of Arts and Sciences, Qatar University, Doha 2713, Qatar; \\ aelshafie@qu.edu.qa (A.S.E.-S.); as1205935@qu.edu.qa (A.A.); ahmedissa@qu.edu.qa (A.A.I.) \\ * Correspondence: marwasaid@qu.edu.qa; Tel.: +974-4403-4675; Fax: +974-4403-4651
}

Received: 22 October 2019; Accepted: 7 November 2019; Published: 13 November 2019

check for updates

\begin{abstract}
Biosorptive removal of basic fuchsin (BF) from wastewater samples was achieved using the recycled agro-wastes of pistachio nut shells (PNS). Seven adsorbents were developed; raw shells (RPNS) and the thermally activated biomasses at six different temperatures $\left(250-500^{\circ} \mathrm{C}\right)$. Two measures were implemented to assess the performance of utilized adsorbents; \%removal (\%R) and adsorption capacity $\left(q_{e}\right)$. RPNS proved to be the best among the tested adsorbents. A smart approach, definitive-screening design (DSD) was operated to test the impact of independent variables on the adsorption capacity of RPNS. pH, adsorbent dose (AD), dye concentration (DC), and stirring time (ST), were the tested variables. Analysis of variance (ANOVA), control, and quality charts helped establishing regression model. Characterization was performed using Fourier- transform infrared (FT-IR)/Raman spectroscopies together with thermogravimetric analysis (TGA) and scanning electron microscopy (SEM)/energy-dispersive X-ray spectroscopy (EDX) analyses. The surface area and other textural properties were determined using the Brunauer Emmett-Teller (BET) analysis. Removal of $99.71 \%$ of BF with an adsorption capacity of $118.2 \mathrm{mg} / \mathrm{g}$ could be achieved using a factorial blend of $\mathrm{pH}$ $12,100 \mathrm{mg} / 50 \mathrm{~mL}$ of RPNS, and $250 \mathrm{ppm} \mathrm{BF}$ for $20 \mathrm{~min}$. Equilibrium studies reveal that the adsorption is physisorption with adsorption energy of $7.45 \mathrm{~kJ} / \mathrm{mol}$ as indicated by Dubinin-Radushkevich (DR) and Langmuir isotherms. Moreover, adsorption follows pseudo-second-order kinetics with respect to $\mathrm{BF}$ and is controlled by the adsorption rate.
\end{abstract}

Keywords: pistachio nutshells (PNS); definitive-screening design (DSD); basic fuchsin (BF); adsorption capacity $\left(q_{e}\right)$; characterization; equilibrium; kinetics

\section{Introduction}

With the progress of human life and the escalating anthropogenic activities, pollution of water has become a crucial environmental concern. Various contaminants are intimidating the aquatic system. These contaminants include, but not limited to, drugs and pharmaceuticals, heavy metals and anions, plastics and polymers, dyes and pigments, and pesticides [1].

Industries, particularly, textiles, leather, food, and cosmetics encompass using dyes with diverse chemical structures. Consequently, the discharge of these industries is basically 'huge' amounts of intensively colored wastewaters. Release of such an effluent into the receiving water bodies causes a direct mutilation of water quality in terms of the aesthetic properties (color, $\mathrm{pH}$, salinity, total organic carbon (TOC), suspended solids, etc.). Such a change negatively impacts the ecosystem. Just thinking about the capability to restrain the photosynthetic ability of water plants and microorganisms, shows the magnitude of the problem. This effect is worsened by the diverse structure of these dyes and their resistance to biodegradation. The negative impact does only involve the environment but also extends to human health with reported carcinogenic activity [2-5]. 
Basic fuchsin (BF), also known as Basic Violet 14, is chemically recognized as benzenamine, 4-[(4-aminophenyl) (4-imino-2,5-cyclohexadien-1-ylidene) methyl]-2-methyl hydrochloride, Figure 1. BF is a mixture of dyes (rosaniline, pararosaniline, new fuchsine, and Magenta II) that is commonly used in gram-staining and in a mixture with phenol for acid-fast staining of mycobacterium (tuberculosis and leprosy) in the procedure known as Ziehl-Neelsen [6,7]. Moreover, BF is widely used in textile and leather industries. Yet, the safety data sheet of BF shows that the dye is inflammable and might cause skin and eye irritations. Moreover, the ingestion of BF might cause internal organs' impairment and repeated exposure is usually associated with nervous system damage with different symptoms [8-10].

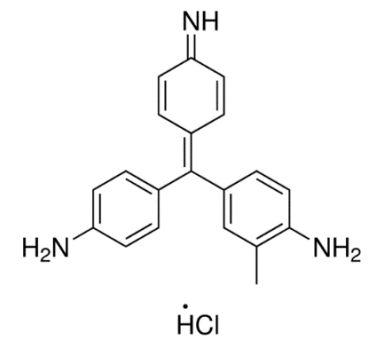

Figure 1. Chemical structure of basic fuchsin (BF).

Keeping in mind these toxic effects and the associated changes in the eco-system, the inevitability for dyes' removal and decolorization of water becomes evident. A literature survey shows that several approaches have been reported for the removal of dyes from aquatic bodies. However, insofar as BF removal is concerned, only a few trials were reported in the literature [10-13]. Reported techniques were mainly based on adsorption (either physisorption or chemisorption) of target dyes on an adsorbent recycled from agricultural/animal waste products [14-18].

A common feature among all the adopted trials is the intimate attempts to develop the model or the ideal adsorbent. Such an adsorbent must have particular criteria such as availability at low-cost and without extensive preceding treatment, liability for regeneration, the possibility for application on a large scale, and be green or in other words does not further contaminate the environment or produce a toxic sludge [19-24]. Activated carbons are promising adsorbents, yet, being expensive and with an inability to be revitalized they confine their applications on the large scale [25]. Yet, developing such an adsorbent from a natural source such as recycled agricultural/animal wastes ensures to a high extent the availability of these criteria.

Pistachio nutshells (PNS) are a by-product of pistachios; one of the most known nut trees worldwide that belongs to the cashew family (Anacardiaceae) [26]. As a desert plant, pistachio can tolerate harsh conditions of temperature and salinity but not humidity. The tree origin is mainly Asia (central and western) with Iran being the top producer [26,27]. As is known, pistachio is commonly used as a snack (fresh or roasted) as well as being an ingredient of deserts, ice-creams, sauces, pastes, and butters. Pistachio shells are usually thrown away after eating the kernel with no further use and their fate is either incineration or dumping. As per the Food and Agriculture Organization (FAO) reports, around $30 \times 10^{6}$ tons of PNS are dumped annually, an issue that negatively impacts the environment [28].

Therefore, it is quite interesting to explore PNS as an adsorbent for the remediation of wastewater from dyes. Since the objective of the current approach is to develop a model adsorbent, variables affecting the adsorption process ( $\mathrm{pH}$, adsorbent dose (AD), dye concentration (DC), and stirring time (ST)) have been optimized through a novel methodology, definitive screening design (DSD) [29]. This design and to the best of our knowledge, has not been explored before for optimizing the adsorption process. Moreover, most of the reported techniques that employ pistachios' by-products (hull, shells, etc.) as adsorbents are using the conventional methodology; one-variable-at-a-time (OVAT), for studying the adsorption process [30-34]. Table 1 summarizes most of the efforts that used pistachios by-products as an adsorbent. Moreover, it shows also some of the methods reported in literature for removing BF $[10,11]$. 
Table 1. Evaluation of the performance of pistachio nutshells (PNS) prepared in the current approach in comparison with PNS as reported in literature as well as the other adsorbents used to remove BF.

\begin{tabular}{|c|c|c|c|c|c|c|c|}
\hline Adsorbent & Modification Method & $\begin{array}{c}\text { Analytical } \\
\text { Approach Used }\end{array}$ & $\begin{array}{l}\text { Surface Area } \\
\left(\mathrm{m}^{2} / \mathrm{g}\right)\end{array}$ & Adsorbate & $\begin{array}{c}\text { Adsorption } \\
\text { Capacity }(\mathrm{mg} / \mathrm{g})\end{array}$ & $\begin{array}{l}\text { \%Removal } \\
\text { (\%R) }\end{array}$ & Ref. \\
\hline $\begin{array}{l}\text { Raw Pistachio } \\
\text { Nutshells (RPNS) }\end{array}$ & $\begin{array}{l}\text { Please see the experimental section of the } \\
\text { current approach }\end{array}$ & $\begin{array}{l}\text { Multivariate } \\
\text { analysis-DSD }\end{array}$ & 4.24 & $\mathrm{BF}$ & 118.2 & $99.71 \%$ & $\begin{array}{c}\text { Current } \\
\text { work }\end{array}$ \\
\hline Pistachio shell & $\begin{array}{l}\text { Pistachio shell was washed several times, and dried at } \\
70^{\circ} \mathrm{C} \text {. The dried biomass was then grounded and used. }\end{array}$ & $\begin{array}{l}\text { One-variable at a } \\
\text { time (OVAT) }\end{array}$ & ND & $\begin{array}{l}\text { C.I. Reactive } \\
\text { Red } 238\end{array}$ & 109.35 & ND & [30] \\
\hline $\begin{array}{l}\text { Pistachio hull } \\
\text { powder (PHP) }\end{array}$ & $\begin{array}{l}\text { Raw hull waste was used following air-drying for three } \\
\text { days, crushed, powdered, and then sieved. }\end{array}$ & OVAT & 1.04 & $\mathrm{Cr}(\mathrm{VI})$ & 116.3 & $99 \%$ & [31] \\
\hline $\begin{array}{l}\text { Pistachio hull } \\
\text { powder (PHP) }\end{array}$ & $\begin{array}{l}\text { Raw hull waste was used following air-drying for three } \\
\text { days, crushed, powdered, and then sieved. }\end{array}$ & OVAT & 1.04 & $\begin{array}{l}\text { Methylene } \\
\text { Blue (MB) }\end{array}$ & 602 & $99.7 \%$ & [32] \\
\hline $\begin{array}{l}\text { Pistachio Shell } \\
\text { Carbon (PSC) }\end{array}$ & $\begin{array}{c}\text { Pistachio shells were washed, dried at } 80^{\circ} \mathrm{C} \text {, and then } \\
\text { placed in muffle furnace for } 1 \mathrm{~h} \text { at } 750^{\circ} \mathrm{C} \text {. Obtained } \\
\text { carbon was grounded, sieved, washed, and then dried } \\
\text { for further use. }\end{array}$ & OVAT & 814.23 & $\mathrm{~Pb}(\mathrm{II})$ & 24.0 & $82.9 \%$ & [33] \\
\hline $\begin{array}{l}\text { Pistachio nutshell } \\
\text { activated carbon } \\
\text { (PSAC)-microwave } \\
\text { assisted } \mathrm{KOH} \\
\text { activation }\end{array}$ & $\begin{array}{c}\text { Pistachio nutshell char was soaked in potassium } \\
\text { hydroxide }(\mathrm{KOH}) \text { with the ration of (char: } \mathrm{KOH}) 1: 1.75 \\
\text { (wt \%). The activation step was done in a glass reactor } \\
\text { inside a modified microwave oven with a power of } 600 \\
\mathrm{mV} \text { and for } 7 \mathrm{~min} \text {. }\end{array}$ & OVAT & ND & $\begin{array}{l}\text { Methylene } \\
\text { Blue (MB) }\end{array}$ & 296.57 & ND & [34] \\
\hline $\begin{array}{l}\text { - Bottom ash } \\
\text { - Deoiled soya }\end{array}$ & $\begin{array}{l}\text { Adsorbents were washed, dried, and then treated with } \\
\mathrm{H}_{2} \mathrm{O}_{2} \text { for } 24 \mathrm{~h} \text {. The product obtained was kept in an } \\
\text { oven at } 100^{\circ} \mathrm{C} \text {. Bottom ash was further activated in a } \\
\text { furnace at } 500^{\circ} \mathrm{C} \text { for } 15 \mathrm{~min} \text {. in presence of air. }\end{array}$ & OVAT & $\begin{array}{l}1.58-1.79 \\
3.21-3.42\end{array}$ & $\mathrm{BF}$ & ND & $\begin{array}{l}89-83.75 \% \\
98-94.25 \%\end{array}$ & [10] \\
\hline $\begin{array}{l}\text { Calcined Mussel } \\
\text { Shell (CMS) }\end{array}$ & $\begin{array}{l}\text { Mussel shells were collected, washed, dried at } 378 \mathrm{~K} \text { for } \\
12 \mathrm{~h} \text {, powdered, and then calcined at } 1173 \mathrm{~K} \text { for } 2 \mathrm{~h} \text {. } \\
\text { Obtained residue was washed and dried at } 353 \mathrm{~K} \text { for } 24 \\
\mathrm{~h} \text {, finely chopped and ground, washed again with } \\
\text { distilled water, dried overnight at } 378 \mathrm{~K} \text {, and then } \\
\text { calcined at a heating rate of } 2 \mathrm{~K} / \mathrm{min} \text { to } 673 \mathrm{~K} \text { for } 4 \mathrm{~h} \text {. }\end{array}$ & OVAT & ND & $\mathrm{BF}$ & 141.65 & $\sim 90 \%$ & [11] \\
\hline
\end{tabular}


Application of such a design; (DSD), guarantees the preservation of method greenness where the lowest amount of resources (chemicals, energy, efforts, etc.) are utilized. Moreover, the obtained data can be treated with a high degree of inevitability. The response variable measured in the current investigation is the adsorption capacity $\left(q_{e}\right)$. The target is to optimize the adsorption process with a maximum $q_{e}$ and the fewest experimentations. Investigation of the adsorbent surface using Fouriertransform infrared (FT-IR) and Raman spectroscopies, scanning electron microscopy (SEM) will be conducted. The determination of the surface area will be done using Brunauer Emmett-Teller (BET) analysis. Thermogravimetric analysis (TGA) of the adsorbent will be conducted. Kinetics and equilibrium studies will be approached to decide upon the nature of the adsorption process.

\section{Materials and Methods}

\subsection{Materials and Reagents}

All reagents and chemicals were of analytical grade and were used as purchased. Sodium hydroxide, sodium tetraborate-10-hydrate $\left(\mathrm{Na}_{2} \mathrm{~B}_{4} \mathrm{O}_{7} \cdot 10 \mathrm{H}_{2} \mathrm{O}\right)$, and hydrochloric acid were procured from Sigma-Aldrich (Germany). Ultrapure water (18.2 M 2 ) was used to prepare and dilute dye solutions. Basic fuchsin was the product of Fluka (Germany). The $\mathrm{pH}$ of BF solutions was adjusted using a mixture of $\left(\mathrm{Na}_{2} \mathrm{~B}_{4} \mathrm{O}_{7} .10 \mathrm{H}_{2} \mathrm{O}, 50 \mathrm{mM}\right)$ and $0.1 \mathrm{M} \mathrm{NaOH}$ or $0.1 \mathrm{M} \mathrm{HCl}$. Further adjustments of $\mathrm{pH}$ were done using small aliquots of $0.1 \mathrm{M} \mathrm{NaOH}$ and $0.1 \mathrm{M} \mathrm{HCl}$. The color of the dye did not change over the investigated $\mathrm{pH}$ range.

\subsection{Instrumentation and Software}

Absorbance measurements were performed using a UV-Vis spectrophotometer (Agilent diode-array, CA, USA) with $10 \mathrm{~mm}$ matched quartz cells. The $\mathrm{pH}$ of samples was measured using a Jenway $\mathrm{pH}$ meter (Jenway, Staffordshire, UK). Separation of the supernatant was done by the aid of a centrifuge (ST8 Benchtop, Thermo Scientific, Waltham, MA, USA). Scanning electron microscopy (SEM, FEI, Quanta 200, Thermo Scientific, Waltham, MA, USA) and energy-dispersive X-ray spectroscopy (EDX) were utilized to study the surface morphology of PNS derived adsorbents. Fourier transform infrared radiation (FT-IR, Bruker Alpha, MA, USA) was used to recognize the functional groups on the surface of the prepared adsorbent. The Raman spectrum was attained in the range from 50-3500 $\mathrm{cm}^{-1}$ using a DXRTM 2 Raman microscope (Thermo Scientific, Waltham, MA, USA), with a laser beam at $532 \mathrm{~nm}$ as excitation source and $10 \mathrm{~mW}$ power. Thermal gravimetric analyzer (TGA, PerkinElmer-TGA400) was employed to investigate the thermal stability of the prepared PNS adsorbents at a temperature range of $50-800{ }^{\circ} \mathrm{C}$.

Determination of surface area, pore size and volume were performed using a Micromeritics ASAP2020 Accelerated Surface Area and Porosimetry System. Degassing of samples was initially employed followed by investigating $\mathrm{N}_{2}$ adsorption-desorption. Using the $\mathrm{N}_{2}$ isotherms collected at 77K and employing the Brunauer Emmett-Teller (BET) equation, surface area was determined. Pore volume was established using the t-plots and the Barrett-Joyner-Halenda (BJH) equation.

Minitab $^{\circledR} 18$ software was purchased from Minitab Inc., State College, PA, USA, and was used to construct the selected design.

\subsection{Preparation of Adsorbent}

Pistachios were purchased from local stores in Doha-Qatar. Purchased samples were selected as non-roasted and non-salted. Collected samples were emptied from the kernel, washed with tap water followed by distilled water several times. Clean shells were dried at $60^{\circ} \mathrm{C}$ for five consecutive days, then grinded using an electrical grinder, sieved in a mesh size $(1 \mathrm{~mm})$, and then divided into two portions. The first portion was kept in sealed vials in the desiccator and labelled as raw pistachio nutshells (RPNS). The second portion was further divided and thermally treated in the oven at different temperatures $\left(250-500^{\circ} \mathrm{C}\right)$. Thermally treated portions were labelled as PNS250, PNS300, PNS350, 
PNS400, PNS450, and PNS500, where the number symbolizes the temperature at which the PNS was treated.

\subsection{Preparation of Adsorbate}

Water samples artificially contaminated with BF were prepared by dissolving the prerequisite amounts of the dye in ultrapure water to final concertation of $100 \mathrm{ppm}$ stock solution. Serial dilutions of the dye were prepared in the same solvent and the $\mathrm{pH}$ was adjusted to the desired value. Three calibration curves of $\mathrm{BF}$ at the tested $\mathrm{pH}$ levels (Table 2, low, mid, and high) were constructed by measuring different concentrations of BF at $547 \mathrm{~nm}$.

Table 2. Screened factors and their levels as well as the measured response variables.

\begin{tabular}{cccc}
\hline Variables/Codes/Units & Lower Level (-1) & Mid (0) & Upper Level (+1) \\
\hline $\mathrm{pH}$ (pH, A, pH unit) & 2 & 7 & 12 \\
Dye concentration (DC, B, ppm) & 50 & 150 & 250 \\
Adsorbent dose (AD, C, mg/50 mL) & 100 & 300 & 500 \\
Stirring time (ST, D, min.) & 20 & 130 & 240 \\
\hline Response “Y" & \multicolumn{3}{c}{$q_{e}$-Adsorption capacity (mg/g) } \\
\hline
\end{tabular}

\subsection{Evaluation of The Adsorption Capability of Prepared Adsorbent(s)}

Equations (1) and (2) were used to evaluate the performance of the prepared adsorbents in terms of $\%$ removal (\%R) as well as the adsorption capacity $\left(q_{e}\right)$. The experimental setup of the proposed design is shown in Table 3. Two series of $15 \mathrm{~mL}$ centrifuge tubes were prepared, and the respective amount of the AD was added, followed by the BF dye solution (pH adjusted as per Table 3). Blanks were similarly prepared but without BF. Tubes were then centrifuged at $4200 \mathrm{rpm}$ for the ST listed in Table 3. The absorbance of the supernatant was measured using spectrophotometry.

$$
\begin{gathered}
(\% \mathrm{R})=\frac{C_{0}-C_{e}}{C_{0}} \times 100 \%, \\
\left(q_{e}\right)=\frac{C_{0}-C_{e}}{W} V,
\end{gathered}
$$

where $C_{e}\left(\mathrm{mg} \mathrm{L}^{-1}\right)$ is the concentration of BF aqueous solution at equilibrium, $C_{0}\left(\mathrm{mg} \mathrm{L}^{-1}\right)$ is the initial concentration of $\mathrm{BF}$ in aqueous solution, $V$ is the volume of the solution in Liter (L), and $W$ is the weight of the adsorbent in (g).

\subsection{Design of Experiments (DoE)}

DSD was the factorial design selected to conduct the current investigation. A single response, adsorption capacity $\left(q_{e}\right)$, was optimized as a function of four independent variables, Table 2 . Table 3 shows the design matrix that involved 13 basic runs in two replicates totaling 26 runs with two central points. Runs were conducted in two blocks. The full quadratic model was obtained by including blocks in the model.

\subsection{Equilibrium and Kinetics Studies}

For the equilibrium studies, a stock solution of $1000 \mathrm{ppm}$ BF was prepared. Further dilutions of the stock solution; 40-400 ppm were prepared in the same solvent and the $\mathrm{pH}$ was adjusted to $\mathrm{pH}$ $12.00 \pm 0.20$ using borate buffer solution. Equal amounts of RPNS $(0.1 \mathrm{~g} \pm 0.005)$ were added to $13 \mathrm{~mL}$ of the previously prepared solutions and then the solution was shaken using the automatic shaker at $150 \mathrm{rpm}$ for $2 \mathrm{~h}$ and then filtered. Absorbance of the filtrate was measured at $547 \mathrm{~nm}$. On the other hand, the kinetics study was conducted using $200 \mathrm{~mL} \mathrm{BF}$ dye solution (200 ppm, pH $12.00 \pm 0.20$ ) and 
$\sim 1.5 \mathrm{~g}$ of RPNS with shaking. One sample was taken at a time range around $1 \mathrm{~min}$. for a time span of $18 \mathrm{~min}$.

Table 3. Design matrix together with observed and predicted responses.

\begin{tabular}{cccccccc}
\hline \multirow{2}{*}{ Run } & \multicolumn{3}{c}{ Coded Levels of Variables } & \multicolumn{3}{c}{ Response (Y, Adsorption Capacity, $q_{\boldsymbol{e}}$ ) } \\
\cline { 2 - 7 } & $\mathbf{A}^{\mathbf{a}}$ & $\mathbf{B}^{\mathbf{b}}$ & $\mathbf{C}^{\mathbf{c}}$ & $\mathbf{D}^{\mathbf{d}}$ & ${ }^{*}$ Obs. & * Pred. $^{*}$ ** $\% \mathbf{E r}$ \\
\hline 01 & -1 & +1 & +1 & -1 & 23.97 & 23.89 & 0.33 \\
02 & 0 & 0 & 0 & 0 & 23.66 & 24.05 & 1.65 \\
03 & -1 & -1 & +1 & +1 & 4.85 & 4.83 & 0.41 \\
04 & -1 & -1 & +1 & +1 & 4.85 & 4.84 & 0.21 \\
05 & +1 & +1 & -1 & -1 & 119.3 & 118.8 & 0.42 \\
06 & -1 & -1 & 0 & -1 & 8.09 & 7.99 & 1.24 \\
07 & -1 & +1 & +1 & -1 & 23.63 & 23.89 & 1.10 \\
08 & -1 & +1 & -1 & 0 & 114.9 & 112.8 & 1.83 \\
09 & 0 & -1 & -1 & -1 & 23.95 & 23.92 & 0.13 \\
10 & 0 & 0 & 0 & 0 & 24.41 & 24.05 & 1.47 \\
11 & -1 & +1 & -1 & 0 & 112.3 & 112.8 & 0.45 \\
12 & -1 & -1 & 0 & -1 & 7.93 & 7.99 & 0.76 \\
13 & +1 & -1 & +1 & 0 & 4.91 & 4.98 & 1.43 \\
14 & +1 & -1 & -1 & +1 & 24.63 & 24.38 & 1.02 \\
15 & -1 & 0 & -1 & +1 & 67.98 & 68.40 & 0.62 \\
16 & 0 & +1 & +1 & +1 & 24.86 & 24.79 & 0.28 \\
17 & +1 & -1 & -1 & +1 & 24.46 & 24.38 & 0.33 \\
18 & +1 & 0 & +1 & -1 & 14.91 & 14.82 & 0.60 \\
19 & -1 & 0 & -1 & +1 & 67.70 & 68.40 & 1.03 \\
20 & 0 & +1 & +1 & +1 & 24.84 & 24.79 & 0.20 \\
21 & +1 & +1 & 0 & +1 & 41.33 & 41.50 & 0.41 \\
22 & +1 & +1 & -1 & -1 & 118.2 & 118.8 & 0.51 \\
23 & 0 & -1 & -1 & -1 & 23.72 & 23.92 & 0.84 \\
24 & +1 & -1 & +1 & 0 & 4.97 & 4.98 & 0.20 \\
25 & +1 & +1 & 0 & +1 & 41.38 & 41.50 & 0.29 \\
26 & +1 & 0 & +1 & -1 & 14.93 & 14.82 & 0.74 \\
\hline
\end{tabular}

$\mathrm{a}, \mathrm{b}, \mathrm{c}, \mathrm{d}$ A, B, C, and D: Are as defined in the upper section of Table 2. ${ }^{*}$ Obs.: Experimental values, ${ }^{* *}$ Pred.: Predicted values following the process of response transformation. ${ }^{* * *} \%$ Er: $\%$ of prediction error $=\mid($ Obs-Pred. $) / /$ Obs $\times 100$.

\section{Results}

\subsection{Evaluation of Adsorption Efficiency of Tested Adsorbents}

Results shown in Table 4 show that RPNS followed by PNS250 had the best performance, with RPNS being more efficient in terms of $\% \mathrm{R}$ and $q_{e}$. The explanation of these findings will be revealed in the following subsections.

Table 4. A comparison of the adsorption capabilities of the five as-prepared adsorbents in terms of $\% \mathrm{R}$ and adsorption capacity $\left(q_{e}\right)$ using adsorbent dose $(\mathrm{AD})=200 \mathrm{mg} / 50 \mathrm{~mL}, \mathrm{pH}=9$, stirring time $(\mathrm{ST})=$ $30 \mathrm{~min}$, and dye concentration $(\mathrm{DC})=30 \mathrm{ppm}$. Shown responses were calculated using Equations (1) and (2).

\begin{tabular}{ccc}
\hline Adsorbent Sample & \% Removal, $\% \mathbf{R} \pm \mathbf{S D}^{*}$ & Adsorption Capacity, $\boldsymbol{q}_{\boldsymbol{e}}(\mathbf{m g} \mathbf{g}) \pm \mathbf{S D}^{*}$ \\
\hline RPNS & $96.45 \pm 0.60$ & $2.89 \pm 0.08$ \\
PNS250 & $52.13 \pm 0.79$ & $1.56 \pm 0.09$ \\
PNS300 & $30.63 \pm 0.53$ & $0.92 \pm 0.01$ \\
PNS350 & $25.18 \pm 0.42$ & $0.75 \pm 0.03$ \\
PNS400 & $22.46 \pm 0.51$ & $0.67 \pm 0.04$ \\
\hline
\end{tabular}

${ }^{*}$ SD values are the average of three determinations. 


\subsection{Definitive—Screening Design (DSD)}

As indicated earlier, the objective of this treatise is to recycle an agricultural byproduct (pistachio nutshells) into a waste-removal green adsorbent with utmost competency. These objectives could be accomplished using the factorial design as an approach. DSD and the name implies a screening design that does not require a subsequent optimization phase. DSD is a three-level design and the number of runs generated is related to the number of variables $(k)$ by the formula $\mathrm{N}=2 k+1$ or $2 k+3$. Experiments were run following factorial combinations shown by the design matrix and considering the two blocks, Table 3, [29,35-37]. As a design, DSD can provide an estimate for the main effects, factorial interactions as well as the quadratic effects with the lowest number of experiments. One response was considered for the current investigation; $q_{e}$. The target was to maximize the response.

\subsubsection{Data Analysis and Modelling}

Data modelling for each response was performed using the following quadratic equation, Equation (3).

$$
\mathrm{Y}=m_{0}+m_{1} X_{1}+m_{2} X_{2}+\ldots+m_{n} X_{n}+\sum m_{i k} X_{i} X_{k}+\sum m_{i i} X_{i}^{2}
$$

where $Y$ denotes the measured responses, $m_{0}, m_{1}$, etc. are the regression coefficients with $m_{0}$ being a constant, $X_{i}$ is an independent variable $(\mathrm{A}, \mathrm{B}, \mathrm{C}$, or $\mathrm{D})$, and $X_{i} X_{k}$ and $X_{i}^{2}$ are the interaction and quadratic terms, respectively.

The regression equation, (Equation (4)), was obtained following response transformation employing Box-Cox response transformation together with stepwise selection of terms.

$$
\begin{gathered}
\ln \left(q_{e}\right)=2.6945+0.07433 \mathrm{pH}+0.007701 \mathrm{DC}-0.004120 \mathrm{AD}+0.003658 \mathrm{ST}-0.000132 \\
\mathrm{pH} \times \mathrm{DC}-0.000385 \mathrm{pH} \times \mathrm{ST}+0.000004 \mathrm{DC} \times \mathrm{AD}-0.000003 \mathrm{AD} \times \mathrm{ST}
\end{gathered}
$$

$$
\left[R^{2}=99.43 \%, R^{2}-\text { Adj. }=99.04 \%, R^{2}-\text { Pred }=98.31 \%\right]
$$

Values of $R^{2}, R^{2}$ - Adj and $R^{2}$ - Pred, associated with each regression model are shown following Equation (4). As shown, value of the coefficient of determination $\left(R^{2}\right)$ was high implying the goodness-of-fit. Moreover, $R^{2}$ - Adj value was close to that of $R^{2}$ - Pred, signifying the capability of the suggested model to expect the response for any new observation. Value of $R^{2}-$ Pred was not markedly less than that of $\mathrm{R}^{2}$, speculating that the model was not over-fit. The model predicted values for the measured response are shown in Table 3. The percentage of prediction error $(\% \mathrm{Er})$ was employed to amount the precision of the prediction of the model. Values of \%Er were between $0.20-1.83 \%$ [38-41]. The percentage of prediction errors as shown is relatively small (less than $5 \%$ ), inferring that the proposed model has reasonable predictive capabilities.

\subsubsection{Quality Charts and ANOVA}

To attest the statistical significance of tested independent variables, Pareto chart of the standardized effects together with analysis of variance (ANOVA) at 95.0 confidence interval (95.0 CI) were run. Figure 2; Pareto chart, shows that DC and AD were the most influencing main effects, followed by the interaction of $\mathrm{pH} \times \mathrm{CT}$. The extent and the direction of the effect for each of the tested variables can be perceived from the regression equation, Equation (4). As revealed in Equation (4), and while $\mathrm{DC}$ has a positive impact on adsorption capacity, the $\mathrm{AD}$ is negatively impacting the response. Yet, and as per the regression model, $\mathrm{pH}$ has the highest magnitude (with a plus sign), an issue which is not reflected by the Pareto chart. This can be understood by comprehensively looking at the model where the interactions of $\mathrm{pH} \times \mathrm{DC}$ and $\mathrm{pH} \times \mathrm{ST}$ are negatively influencing the adsorption capacity, an issue that a bit diminishes the impact of $\mathrm{pH}$. 


\section{Pareto Chart of the Standardized Effects}

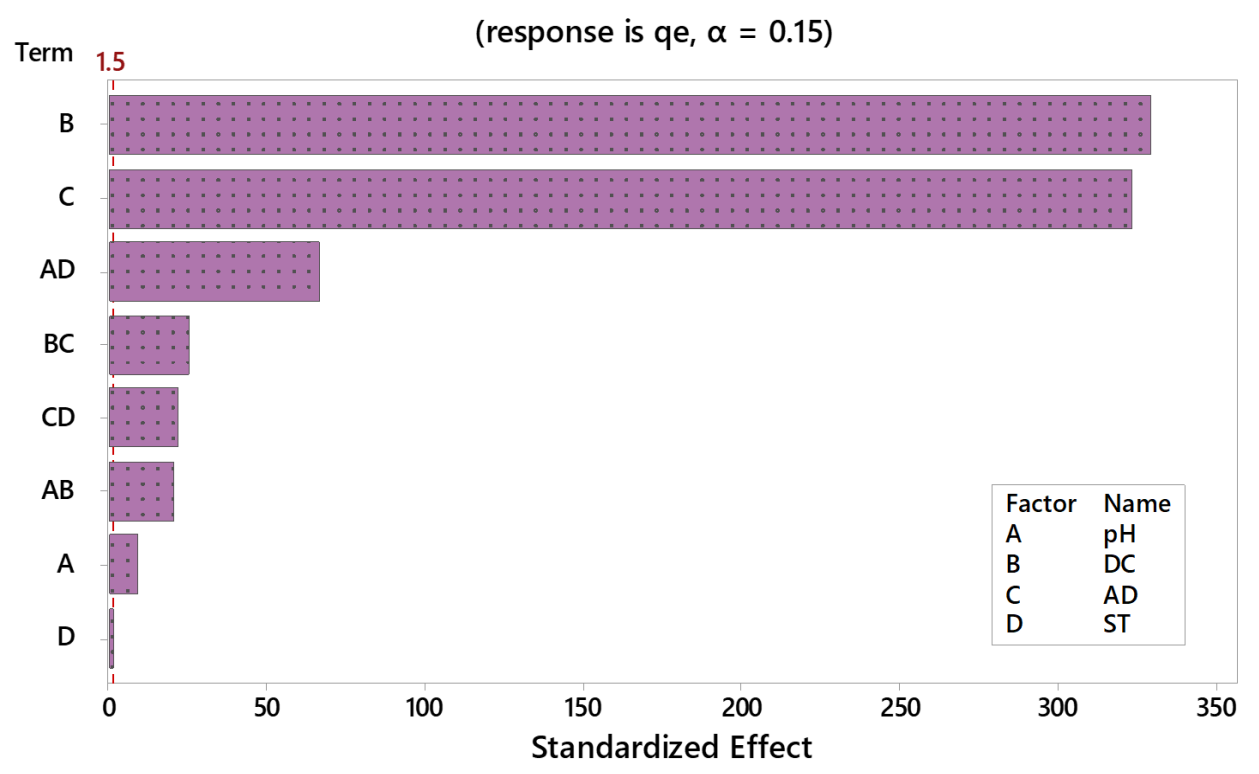

Figure 2. Pareto chart of standardized effects following response transformation. Adsorption capacity $\left(q_{e}, \mathrm{mg} / \mathrm{g}\right)$ is the measured response. Variables exceeding the reference line (red dashed line) are statistically significant.

Residual plots (normal probability plot of residuals, histogram of residuals, residuals versus fit, and residuals versus order, not shown) were employed to test data (residuals') distribution, whether residuals are normally distributed with a constant variance, and whether residuals are independent of one another. Similar conclusions were obtained using the ANOVA testing, Table 5. The statistical significance of tested variables at $95.0 \mathrm{CI}$ was confirmed by $p$-values $<0.05$. Table 5 also shows that F-statistic is relatively large for the model, linear, and two-way interactions implying the statistical significance of the tested variables. On the other hand, F-value was small in case of ST and lack-of-fit with a $p$-value $>0.05$, indicating that the suggested model properly describes the relationship between the response and the predictors.

Table 5. Analysis of variance (ANOVA) for the transformed response.

\begin{tabular}{cccccc}
\hline Source & DF $^{*}$ & Adj SS * & Adj MS & F-Value & $p$-Value \\
\hline Model & 8 & 25.6710 & 3.2089 & 27351.92 & 0.000 \\
\hline Linear & 4 & 25.0458 & 6.2614 & 53371.41 & 0.000 \\
pH & 1 & 0.0096 & 0.0096 & 81.89 & 0.000 \\
AD & 1 & 12.7534 & 12.7534 & 108707.38 & 0.000 \\
DC & 1 & 12.2826 & 12.2826 & 104694.78 & 0.000 \\
ST & 1 & 0.0002 & 0.0002 & 1.60 & 0.222 \\
\hline 2-Way Interactions & 4 & 0.6253 & 0.1563 & 1332.43 & 0.000 \\
pH $\times$ DC & 1 & 0.0509 & 0.0509 & 434.13 & 0.000 \\
pH $\times S T$ & 1 & 0.5227 & 0.5227 & 4455.67 & 0.000 \\
DC $\times$ AD & 1 & 0.0758 & 0.0758 & 646.39 & 0.000 \\
AD $\times$ ST & 1 & 0.0544 & 0.0544 & 463.88 & 0.000 \\
\hline Error & 17 & 0.0020 & 0.0001 & & \\
Lack-of-Fit & 7 & 0.0009 & 0.0001 & 1.12 & 0.419 \\
Pure Error & 10 & 0.0011 & 0.0001 & & \\
\hline Total & 25 & 25.6730 & & &
\end{tabular}

* DF: Degrees of Freedom; Adj SS: Adjusted sums of squares; and Adj MS: Adjusted mean of squares. AD: Adsorbent dose $(\mathrm{mg} / 50 \mathrm{~mL})$; DC: Dye concentration (ppm); and ST: Stirring time (min.). Statistically insignificant variables appear italic. 


\subsubsection{Response Surface Optimization}

Contour plots of the response surface were implemented to articulate the correlation between the measured response and the independent variables. These plots enable measuring the influence of two variables-simultaneously-while the other variables are held constant in two dimensions. Figure 3 shows a 2D plot for adsorption capacity versus the different two factorial combinations. As shown on the graph, $q_{e}>100 \mathrm{mg} / \mathrm{g}$ could be attained for example at a DC of 225-250 ppm and an AD not exceeding $130-140 \mathrm{mg} / 50 \mathrm{~mL}$. Optimum conditions that maximize the response (individual desirability function, $d$ ) were obtained employing the Minitab response optimizer facility. Individual response optimization shows that a $q_{e}$ value of $149.82 \mathrm{mg} / \mathrm{g}$ could be achieved with a $d=1.0000 \mathrm{using}$ a factorial blend of $\mathrm{pH} 2, \mathrm{AD}=100 \mathrm{mg} / 50 \mathrm{~mL}, \mathrm{DC}=250 \mathrm{ppm}$, and ST $=240 \mathrm{~min}$.

\section{Contour Plots of qe}
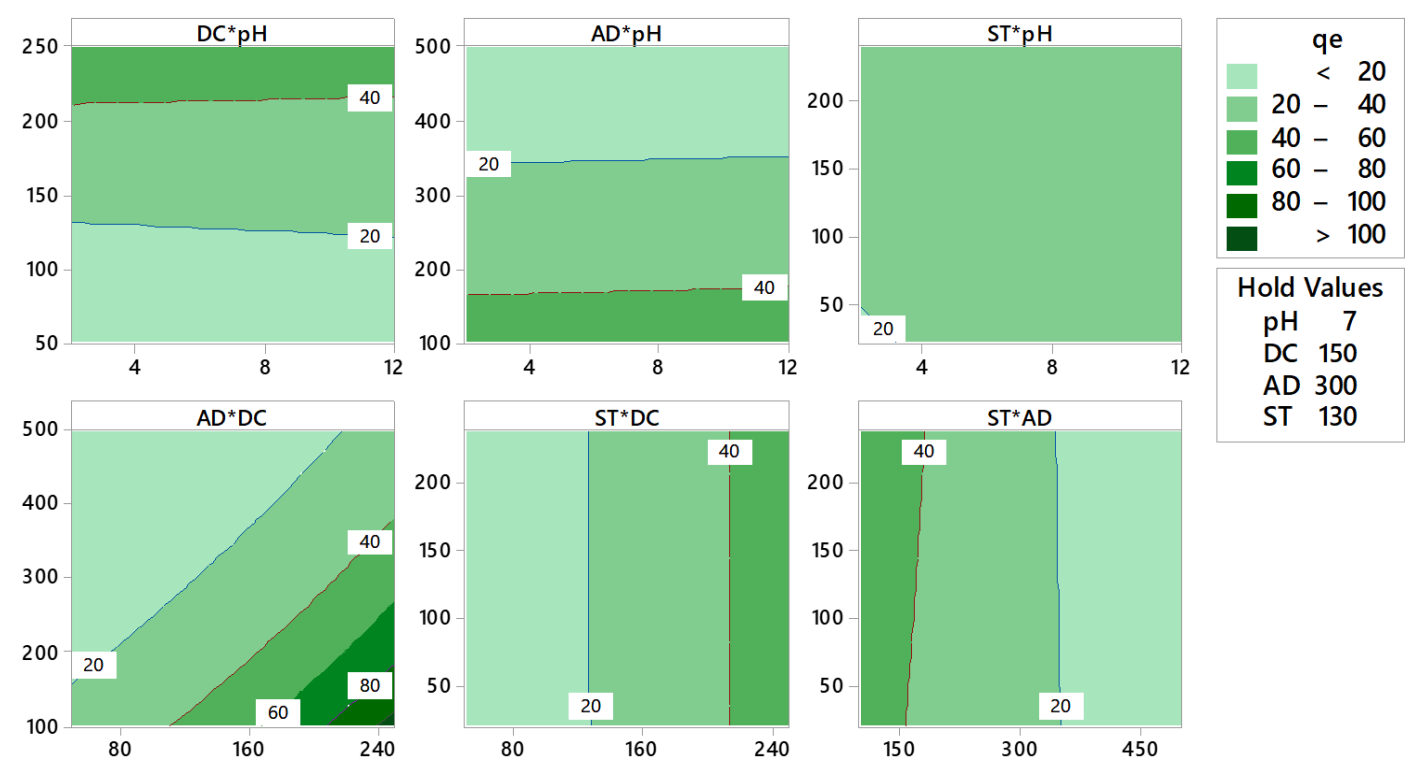

Figure 3. Response contour plots for the adsorption capacity $\left(q_{e}, \mathrm{mg} / \mathrm{g}\right)$. Dark green regions represent regions where maximum adsorption capacity could be obtained using the described factorial combination.

\subsection{Characterization Methods}

\subsubsection{Carbon, Hydrogen, Nitrogen (CHN) Analysis}

Table 6 shows the CHN analysis for RPNS and the thermally activated derived adsorbents (PNS250-PNS500). Obtained results show that the \%C, in general, has increased with the thermal treatment implying the conversion of PNS into activated carbon. This could be attributed to thermal destruction of all the organic matter and subsequent conversion into mainly carbonaceous material with the heat treatment. On the other hand, the concentration of hydrogen has decreased from $6 \%$ in the RPNs to 3\% in PNS500. This would be attributed to the loss of hydrogen with oxygen-water evaporation-as the temperature increases.

As will be shown later in TGA/dTGA and FT-IR analyses sections for RPNS, the raw sample was composed mainly of hemicellulose, cellulose, and lignin with some water and probably some protein. Therefore, the presence of $\mathrm{N}$ could be attributed to the protein content with some contaminations. On the other hand, the carbon content increases with the temperature of treatment up to $350{ }^{\circ} \mathrm{C}$, then there is a change in the carbon content above this temperature. Yang et al. [42], reported that the yield of gasses $\left(\mathrm{H}_{2} \mathrm{O}, \mathrm{CO}, \mathrm{CO}_{2}, \mathrm{H}_{2}, \mathrm{CH}_{4}, \mathrm{C}_{2} \mathrm{H}_{4}\right.$, and $\left.\mathrm{C}_{2} \mathrm{H}_{5}\right)$, as a result of pyrolysis of hemicellulose, cellulose, and lignin materials, differs depending on the temperature and nature of the investigated 
material. For example, and while hemicellulose produces more $\mathrm{CO}_{2}$ upon pyrolysis, lignin yield is mainly $\mathrm{H}_{2}$ and $\mathrm{CH}_{4}$. Therefore, this could explain the observed change in $\% \mathrm{C}$.

Table 6. CHN analysis of raw pistachio nutshells (RPNS) and thermally treated PNS $\left(250-500{ }^{\circ} \mathrm{C}\right)$.

\begin{tabular}{cccc}
\hline Sample Code & N (\%) & C (\%) & H (\%) \\
\hline RPNS & 0.559 & 45.720 & 6.059 \\
PNS250 & 0.595 & 56.313 & 5.369 \\
PNS300 & 0.201 & 66.041 & 4.801 \\
PNS350 & 0.251 & 73.501 & 4.339 \\
PNS400 & 0.204 & 68.184 & 3.948 \\
PNS450 & 0.288 & 91.874 & 3.620 \\
PNS500 & 0.447 & 85.494 & 3.155 \\
\hline
\end{tabular}

\subsubsection{TGA Analysis}

Thermogravimetric analysis of RPNS was performed under $\mathrm{N}_{2}$ and with a heating rate of $10{ }^{\circ} \mathrm{C} / \mathrm{min}$. Data represented in Figure 4 show that the weight loss for the RPNS sample occurs through two main steps;

1. Step 1: Loss of adsorbed water molecules from the sample at a temperature range of $25-100{ }^{\circ} \mathrm{C}$, followed by the loss of crystalline water at $\sim 200{ }^{\circ} \mathrm{C}$, which represents $5.35 \%$ of the sample. In fact, the lost water is relatively lower than what was expected. However, this would be attributed to the probability that and though RPNS was purchased as non-roasted, it might have been exposed to a sort of heat treatment prior to packing and distribution;

2. Step 2: In this step, $>70 \%$ of the sample is decomposed between $\left(200-500{ }^{\circ} \mathrm{C}\right)$ and two major peaks at $290.69^{\circ} \mathrm{C}$ and $359.62^{\circ} \mathrm{C}$ can be observed, which could be attributed to the decomposition of the organic materials present in RPNS and the carbonization of the polymeric material.

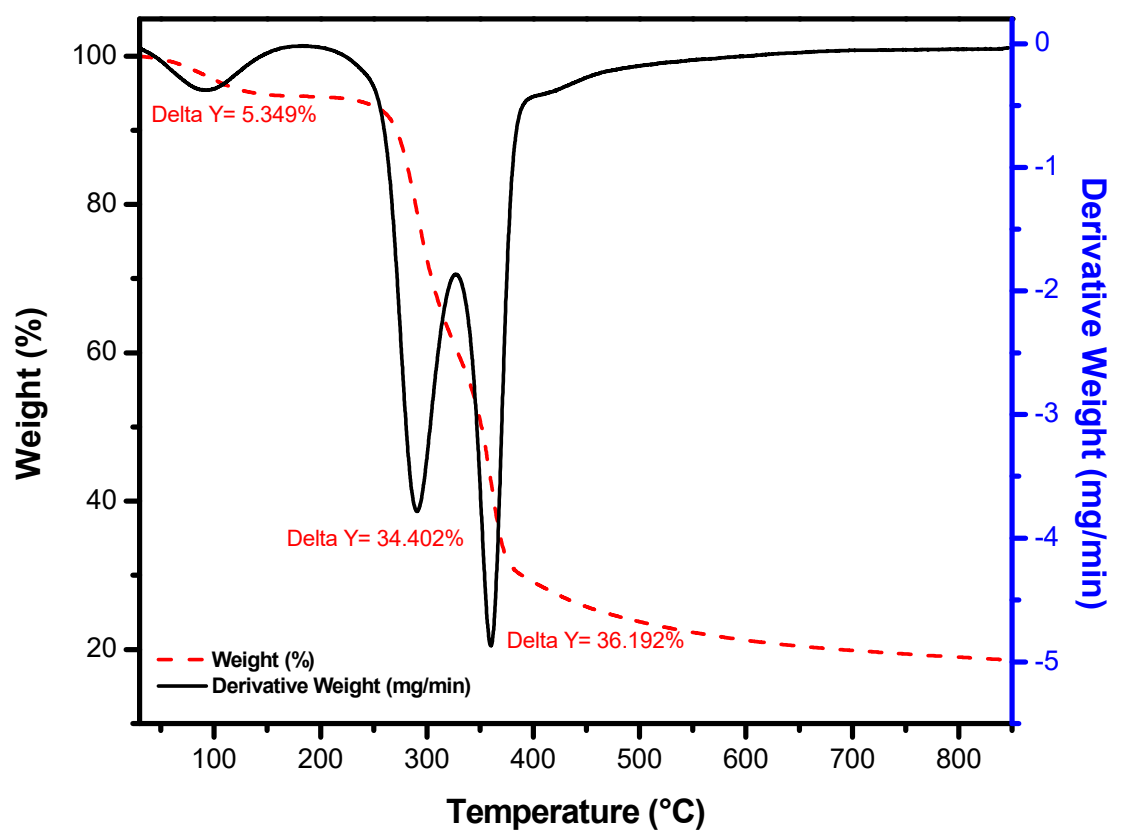

Figure 4. Thermal gravimetric analyzer (TGA) analysis of the raw pistachio nutshells sample at a temperature range $50-800{ }^{\circ} \mathrm{C}$.

\subsubsection{Raman Analysis}

Raman spectra of RPNS and thermally activated sorbents $\left(200-500^{\circ} \mathrm{C}\right)$ are presented in Figure 5 . The spectrum of RPNS and all the thermally activated samples show a clear D- band at $1351 \mathrm{~cm}^{-1}$ 
and a clear G- band at $1585 \mathrm{~cm}^{-1}$. These two peaks are distinctive in the spectra of all carbonaceous materials and their arrangement is the same as graphene oxide. The presence of these two peaks in the RPNS could be attributed to and as previously mentioned to a prior roasting process at a high temperature which results in the formation of carbonaceous material.

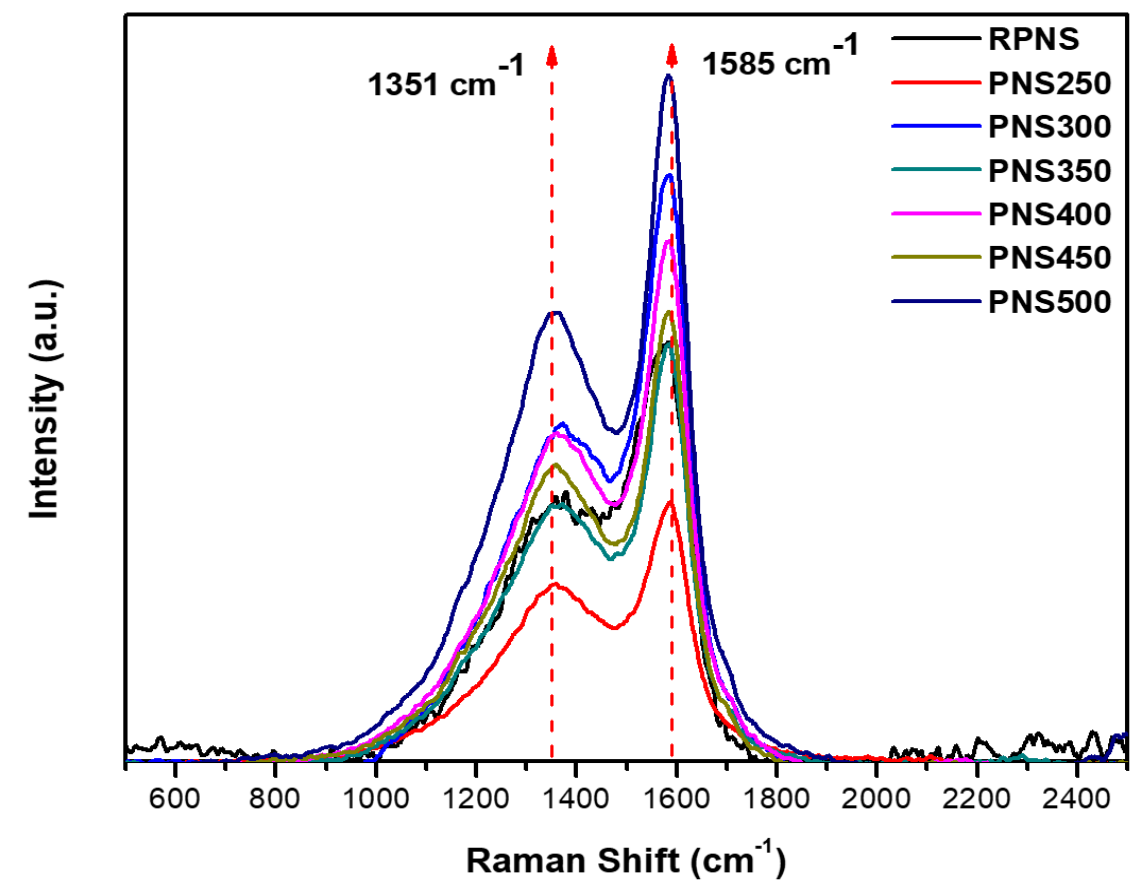

Figure 5. Raman analysis of raw pistachio nutshells and thermally activated samples at different temperatures range from $250-500{ }^{\circ} \mathrm{C}$ (PNS250-PNS500).

As previously reported, the characteristics of the carbon lattice including defects and sizes are presented by the D-band, however, it does not represent the chemical structure of the carbon materials. The wavelength of the laser beam changes the position of the D-band but the G-band identifies the stretching of C-C for the $s p^{2}$ system. Furthermore, the intensity ratio $I_{D}: I_{G}$ has increased from RPNS (0.61) to PNS500 (0.65). This behavior occurred due to the thermal treatment process which increases the defect states in the $s p^{2}$ plane of carbon. The obtained data confirm the formation of activated carbon with higher defects after thermal treatment compared to the roasted one.

\subsubsection{FT-IR Analysis}

FT-IR spectra of RPNS and PNS500 samples is given in Figure 6. Spectrum of RPNS shows the presence of a broad characteristic band at $3327 \mathrm{~cm}^{-1}$ for the stretching vibrations of the $(-\mathrm{OH})$ group [43], a peak at $2909 \mathrm{~cm}^{-1}$ which can be attributed to stretching vibration of aliphatic C-H and a band at $1732 \mathrm{~cm}^{-1}$ which could be attributed to the presence of $\mathrm{C}=\mathrm{O}$ stretching vibration in carboxylic acids. The presence of these peaks confirms the presence of carbonyl function group on the surface of RPNS. Furthermore, the absorption peak at $1590 \mathrm{~cm}^{-1}$ can be associated with the $\mathrm{C}=\mathrm{C}$ stretching in unsaturated ketones. The huge peak at $1027 \mathrm{~cm}^{-1}$ is related to the presence of $\mathrm{C}-\mathrm{O}-\mathrm{C}$, which is characteristic peak in hemicellulose and cellulose $[30,34]$. This spectrum also confirms the presence of small peaks between $1450-1310 \mathrm{~cm}^{-1}$ which could be related to bending vibrations of $\mathrm{O}-\mathrm{H}$ and C-H groups.

On the other hand, the spectrum of the thermally treated sample (PNS500) shows little shifting of the positions of some peaks compared to their analogs in the spectrum of RPNS. For example, the peaks at 1590 and $1732 \mathrm{~cm}^{-1}$ that were attributed to the $C=C$ and $C=O$ groups in RPNS, appear at 1579 and $1740 \mathrm{~cm}^{-1}$ in PNS500. In addition, the spectrum shows the disappearance of some peaks such as the one at $3327 \mathrm{~cm}^{-1}$. Such a behavior might have been caused by the de-hydroxylation that occurs during 
the thermal treatment process. Depending on the TGA/dTGA thermograph and FT-IR spectrum of RPNS, the nutshell of pistachio is formed mainly of hemicellulose, cellulose, and lignin. Therefore, it can be concluded that the thermal activation leads to the removal of hydroxyl, carboxylic, carbonyl, and esters groups in the form of water, $\mathrm{CO}, \mathrm{CO}_{2}$, and small volatile organic compounds [42].
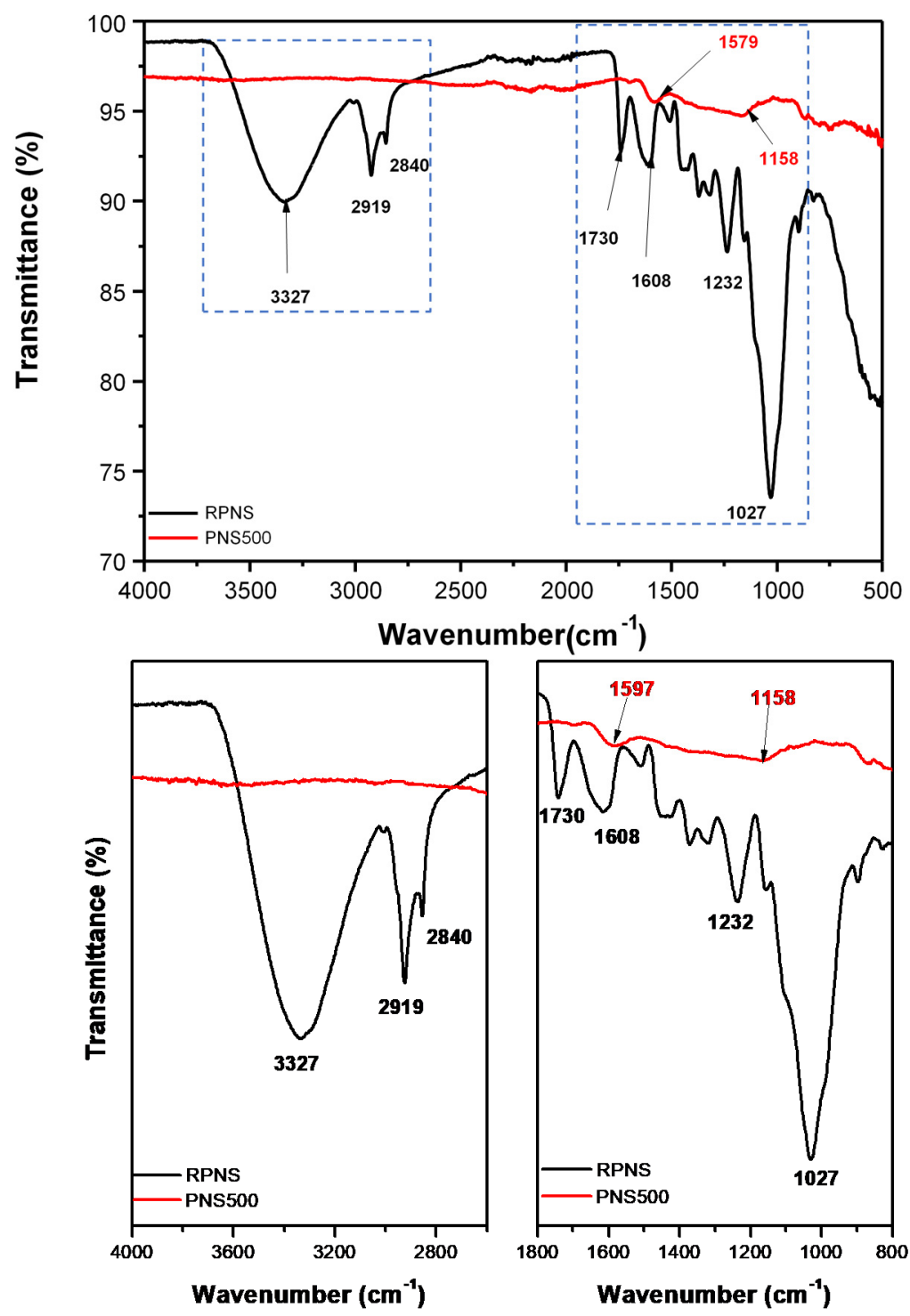

Figure 6. Fourier- transform infrared (FT-IR) spectra of raw pistachio nutshells and thermally treated sample at $500{ }^{\circ} \mathrm{C}(\mathrm{PNS500)}$.

\subsubsection{SEM and EDX Analyses}

The surface morphology of RPNS and the thermally activated samples were studied using SEM. The SEM micrographs shown in Figure 7A indicate the presence of some pores in RPNS. As the temperature used for thermal treatment increases, the number and size of the pores also increase, Figure 7B-D. The advanced pore structure in the thermally treated samples could be attributed to the decomposition of the three major components (hemicellulose, cellulose, and lignin) of the sample at different temperatures, with significantly different patterns in terms of produced gases. This finding was further confirmed by the TGA/dTGA analysis, Figure 5, and was previously reported [42]. Similarly, these findings are in alignment with the BET surface area and TGA analyses of other thermally treated adsorbents [19-21]. 
EDX analysis was used to study the elemental composition of tested adsorbents; RPNS and PNS500. The obtained results confirm that PNS500 was essentially constituted of carbon, 95.21\%, compared to $80.57 \%$ for RPNS. Other elements like $\mathrm{Na}, \mathrm{Mg}$, and $\mathrm{Ca}$ exist, however, their concentration was less than $2 \%$. The obtained data confirm the formation of carbonaceous material following the thermal treatment.
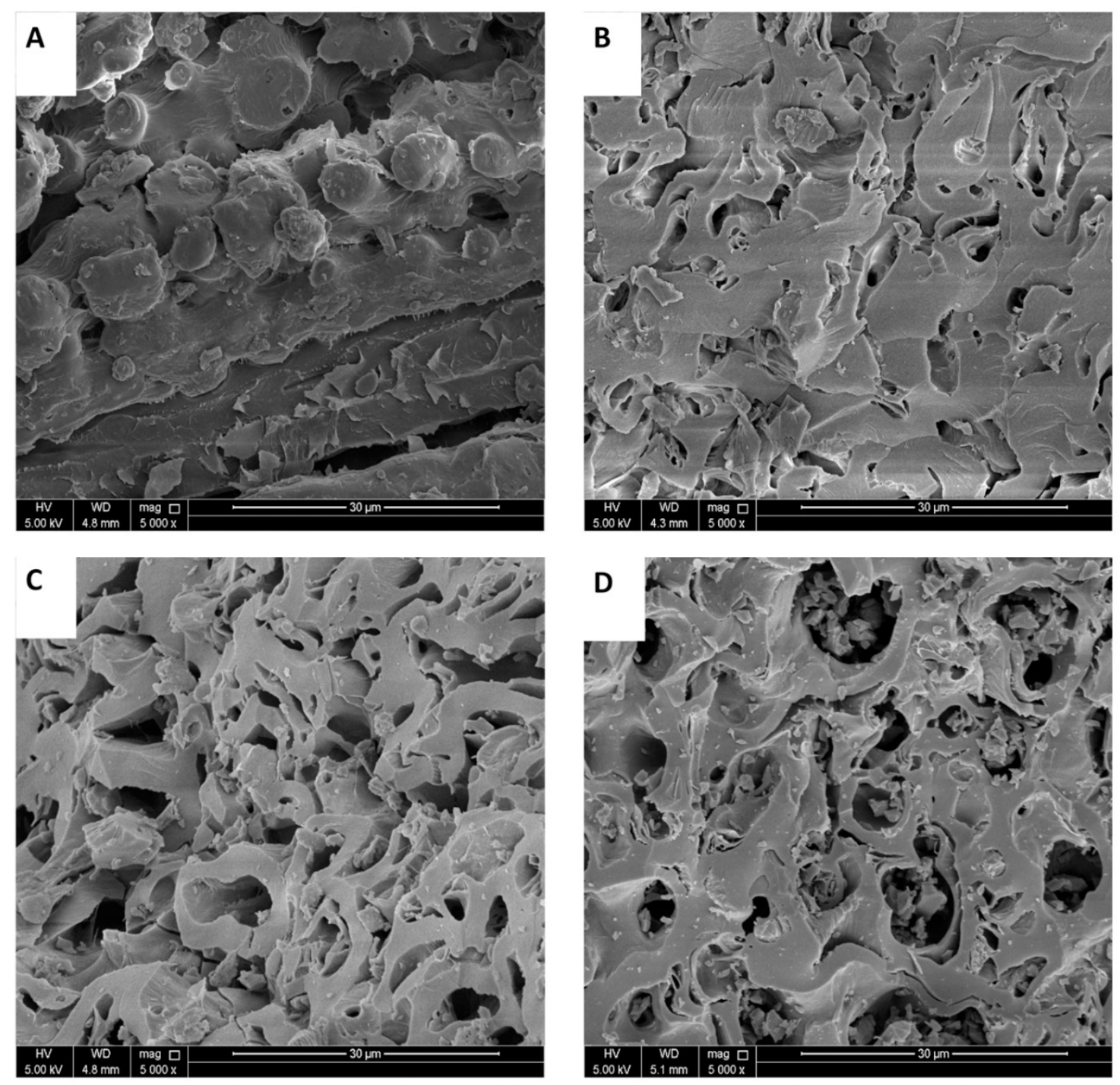

Figure 7. SEM micrographs of (A) RPNS, (B) PNS300, (C) PNS400, and (D) PNS500.

\subsubsection{BET Analysis}

The surface area (SA) of RPNS and thermally treated samples was measured as shown in Table 7. The collected data show that Langmuir SA has increased from 4.24 to $76.94 \mathrm{~m}^{2} / \mathrm{g}$. This huge increase in the SA could be attributed to the thermal treatment process. Furthermore, the total pore volume has increased from 0.008174 to $0.07234 \mathrm{~cm}^{3} / \mathrm{g}$ for RPNS and PNS500 samples, respectively. The average pore radius was found to be $61.7^{\circ} \mathrm{A}$ for RPNS and $89.8^{\circ} \mathrm{A}$ for RPNS350. The obtained data indicate that the thermal treatment process of PNS samples did not have a great impact on the average pore radius and the total pore volume in contrast to the SA. 
Table 7. Brunauer Emmett-Teller (BET) analysis of RPNS and thermally treated PNS.

\begin{tabular}{ccccc}
\hline Parameters & RPNS & PNS250 & PNS350 & PNS500 \\
\hline Langmuir SA $\left(\mathrm{m}^{2} / \mathrm{g}\right) \pm \% \mathrm{Er}$ & $4.24 \pm 0.09 \%$ & $4.62 \pm 0.11 \%$ & $4.72 \pm 0.07 \%$ & $76.94 \pm 0.15 \%$ \\
Total pore volume $\left(\mathrm{cm}^{3} / \mathrm{g}\right)$ & 0.008174 & 0.008711 & 0.01360 & 0.07234 \\
Average pore radius $\left({ }^{\circ} \mathrm{A}\right)$ & 61.7 & 50.6 & 89.8 & 22.7 \\
\hline$\%$ Er: $\%$ Error & \multicolumn{5}{c}{} \\
\hline
\end{tabular}

\subsection{Equilibrium and Kinetics Studies of The Adsorption of BF on RPNS}

Table 4 shows that RPNS had the best adsorption efficiency in terms of adsorption capacity $\left(q_{e}\right)$ and $\%$ R. Therefore, the equilibrium and kinetics studies were conducted using RPNS. These studies are usually used to evaluate the efficiency and validity of any adsorbent. The adsorption isotherms are useful in the determination of the maximum quantity $\left(q_{m}\right)$ that can be adsorbed, the pattern of adsorption on the surface of the biomass, the interaction between adsorbate and adsorbent's surface, and whether it is chemisorption or physisorption. On the other hand, the kinetic studies were used to determine the rate of adsorption, the thickness of the formed layer around the sorbent, and whether the reaction is controlled by diffusion or adsorption mechanisms. The following sections showing studies on the adsorption isotherms as well as the kinetics of the adsorption of BF on RPNS.

\subsubsection{Equilibrium Isotherms}

Four isotherm models were used to investigate the adsorption process of BF on RPNS. These models include Langmuir, Freundlich, Temkin, and Dubinin-Radushkevich (DR) isotherm.

Langmuir isotherm explains the single-layer homogeneous adsorption on a surface, Figure 8A and Table 6. Langmuir equation is shown in Equation (5),

$$
q_{e}=\frac{q_{m} K_{L} C_{e}}{1-K_{L} C_{e}}
$$

where $q_{m}$ is monolayer adsorption capacity and $K_{L}$ is the Langmuir equilibrium coefficient. In addition, the Langmuir equation can be stated using the dimensionless formula, Equation (6):

$$
R_{L}=\frac{1}{1-K_{L} C_{0}}
$$

where $R_{L}$ is the separation factor, and $C_{0}(\mathrm{mg} / \mathrm{L})$ is the initial concentration. The adsorption favorability as reported previously is dependent on the value of $R_{L}$. If $R_{L}$ is $>1$, then the adsorption process is considered as unfavorable and if $R_{L}=1$ in this case the adsorption is linear. On the other hand, if the $R_{L}$ value is between zero and one, then the adsorption is favorable (occurs spontaneously) while if it = 0 , the adsorption is irreversible [31]. The calculated $R_{L}$ value in the current investigation was found to be $<1$ and higher than 0 , implying that the adsorption process was spontaneous, with maximum adsorption $\left(q_{\max }\right)=58.82 \mathrm{mg} / \mathrm{g}$ and a good fit as revealed by the coefficient of determination, $\mathrm{R}^{2}=0.967$.

The Freundlich isotherm used to describe heterogeneous surface energies and given by the equation:

$$
q_{e}=K_{F} C_{e}^{\frac{1}{n}}
$$

Here the $C_{e}$ is the equilibrium concentration of $\mathrm{BF}\left(\mathrm{mg} \mathrm{L}^{-1}\right) ; q_{e}$ is the amount of $\mathrm{BF}$ adsorbed/unit mass $\left(\mathrm{mg} \mathrm{g}^{-1}\right), \mathrm{K}_{\mathrm{F}}\left(\right.$ mole. $\left.^{-1}\right)\left(\mathrm{L} \mathrm{mole}^{-1}\right)^{1 / \mathrm{n}}$, and 1/n, are Freundlich coefficients. The data are shown in Figure $8 \mathrm{~B}$ and Table 8 illustrates lower $\mathrm{R}^{2}$ value, $\mathrm{R}^{2}=0.932$ implying that Freundlich isotherm is not applicable to study the adsorption process of BF on RPNS. On the other hand, the Freundlich coefficient $1 / n$ equals 0.637 and $n=1.569$ meaning that the adsorption process is homogeneous, and adsorption is favorable hence $1 / n<1$. 

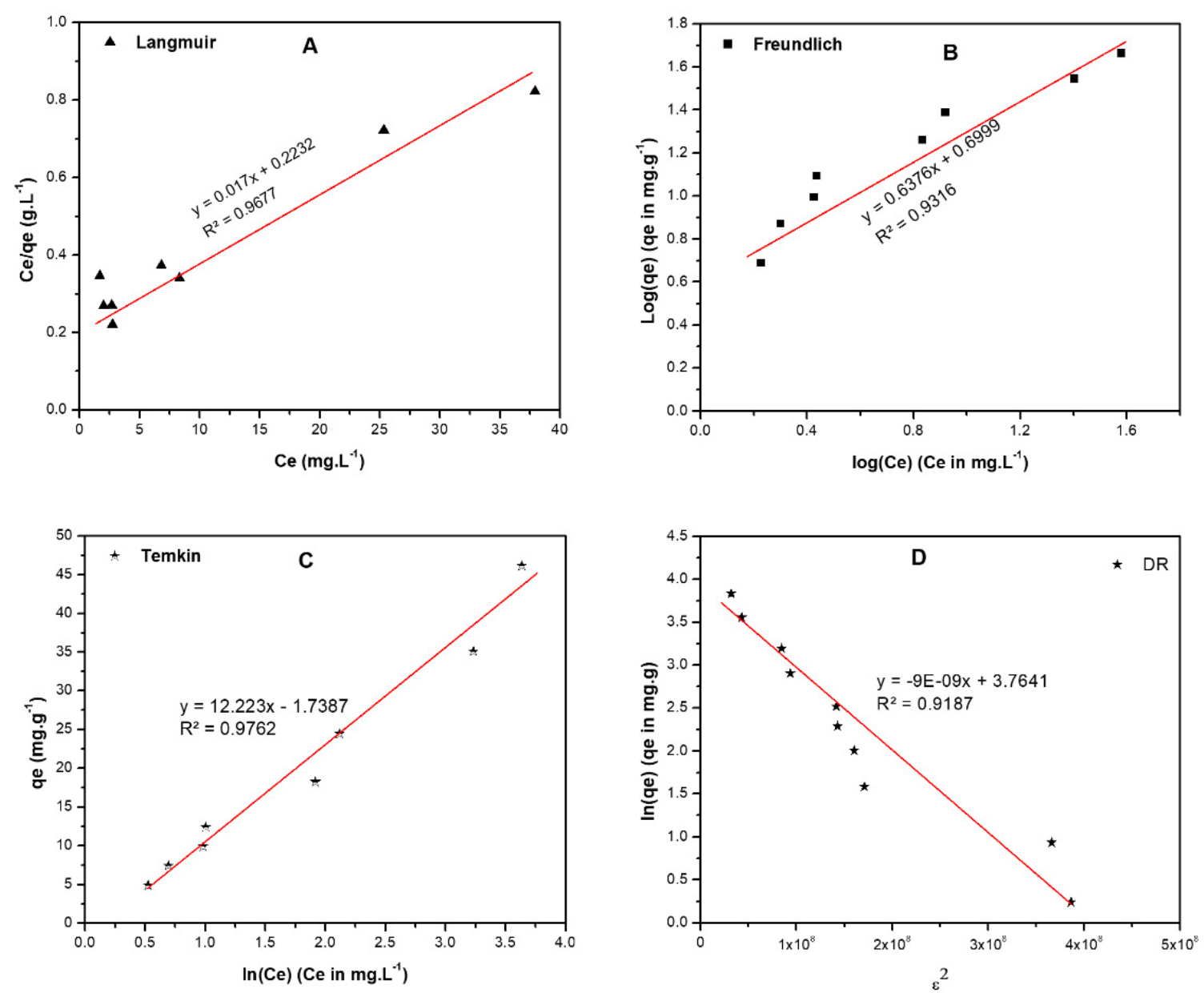

Figure 8. Adsorption isotherms of BF on raw pistachio nutshells including, (A) Langmuir, (B) Freundlich, (C) Temkin, and (D) Dubinin-Radushkevich (DR). The following conditions were used to obtain the isotherms; DC: 40-400 ppm, AD: $0.100 \pm 0.005 \mathrm{~g}, \mathrm{pH}: 12.00 \pm 0.20$, and ST: $2 \mathrm{~h}$.

Table 8. General and linearized equation of Langmuir, Freudlich, Temkin, and Dubinin-Radushkevich isotherms, beside their parameters for the adsorption of BF on RPNS.

\begin{tabular}{|c|c|c|c|}
\hline Isotherm & Equations (Generalized/Linearized Forms) & Parameters & Value \\
\hline \multirow{3}{*}{ Langmuir } & \multirow{3}{*}{$\begin{aligned} q_{e} & =\frac{q_{m} K_{L} C_{e}}{1-K_{L} C_{e}} \\
\frac{C_{e}}{q_{e}} & =\frac{1}{q_{m} K_{L}}+\frac{C_{e}}{q_{m}}\end{aligned}$} & $q_{m}(\mathrm{mg} / \mathrm{g})$ & 58.82 \\
\hline & & $K_{L}\left(\mathrm{~L} \cdot \mathrm{mole}^{-1}\right)$ & 0.076 \\
\hline & & $\mathrm{R}^{2}$ & 0.968 \\
\hline \multirow{3}{*}{ Freundlich } & \multirow{3}{*}{$\begin{array}{c}q_{e}=K_{F} C_{e}^{\frac{1}{n}} \\
\log \left(q_{e}\right)=\log \left(K_{F}\right)+\left(\frac{1}{n}\right) \log \left(C_{e}\right)\end{array}$} & $1 / \mathrm{n}$ & 0.637 \\
\hline & & $K_{F}($ mole $/ \mathrm{g})(\mathrm{L} / \mathrm{mole})^{1 / \mathrm{n}}$ & 5.011 \\
\hline & & $R^{2}$ & 0.932 \\
\hline \multirow{3}{*}{ Temkin } & \multirow{3}{*}{$\begin{array}{c}q_{e}=\frac{R T}{b_{T}} \ln \left(A_{T} C_{e}\right) \\
q_{e}=\frac{R T}{b_{T}} \ln \left(A_{T}\right)+\frac{R T}{b_{T}} \ln \left(C_{e}\right)\end{array}$} & $b_{T}(\mathrm{~J} / \mathrm{mole})$ & 200.6 \\
\hline & & $A_{T}(\mathrm{~L} / \mathrm{mole})$ & 0.867 \\
\hline & & $R^{2}$ & 0.976 \\
\hline \multirow{3}{*}{$\mathrm{DR}$} & $\ln \left(q_{e}\right)=\ln \left(q_{m}\right)-\beta \epsilon^{2}$ & $\beta$ & $9 \times 10^{-9}$ \\
\hline & $\epsilon=R T\left(1+\frac{1}{C_{e}}\right)$ & $\begin{array}{c}E(\mathrm{~kJ} / \mathrm{mole}) \\
q_{\mathrm{s}}(\mathrm{mg} . \mathrm{g})\end{array}$ & $\begin{array}{c}7.45 \\
43.12\end{array}$ \\
\hline & $E=\frac{1}{\sqrt{2 \beta}}$ & $R^{2}$ & 0.918 \\
\hline
\end{tabular}


Temkin isotherm, Figure 8C, gives an idea about the adsorbate/adsorbent interaction by the factor that describes the fact that the heat of adsorption of all the molecules in the layer decreases linearly with the adsorbent-adsorbate interactions. Data shown in Table 8 show that the $\mathrm{R}^{2}$ value $=0.967$ signifying that this isotherm is applicable for studying the adsorption of BF on the RPNS.

Finally, the DR isotherm, Figure 8D was applied to differentiate between the adsorption mechanisms on a heterogeneous surface [31]. The physical adsorption occurs when free energy is $<8.0 \mathrm{~kJ} / \mathrm{mol}$, while the chemical adsorption occurs when free energy is $>8.0 \mathrm{~kJ} / \mathrm{mol}$. The free energy for adsorption of BF on RPNS is physical because the free energy $=7.45 \mathrm{~kJ} / \mathrm{mol}$ as shown in Table 8 . On the other hand, this isotherm is not applicable for the adsorption of BF on RPNS because the $\mathrm{R}^{2}$ value $=0.913$.

\subsubsection{Kinetics Studies}

Four kinetics models; namely pseudo-first-order (PFO), pseudo-second-order (PSO), Elovich, and Weber-Morris (W-M) were applied to simulate the kinetics of the adsorption of BF onto RPNS. Figure 9A,B show the plots of $\left[\ln \left(q_{e}-q_{t}\right)\right.$ versus time] and [time $/ q_{t}$ versus time] for the PFO and PSO kinetic models, respectively. The calculated parameters of the two models are tabulated in Table 9. Comparing the coefficient of determination values $\left(R^{2}\right)$ of the two models, the experimental data were in good agreement with the PSO model $\left(R^{2}=0.995\right)[19,44,45]$. Therefore, the reaction can be represented as:

$$
B F+R P N S \stackrel{k}{\rightarrow}\{B F-R P N S\}
$$
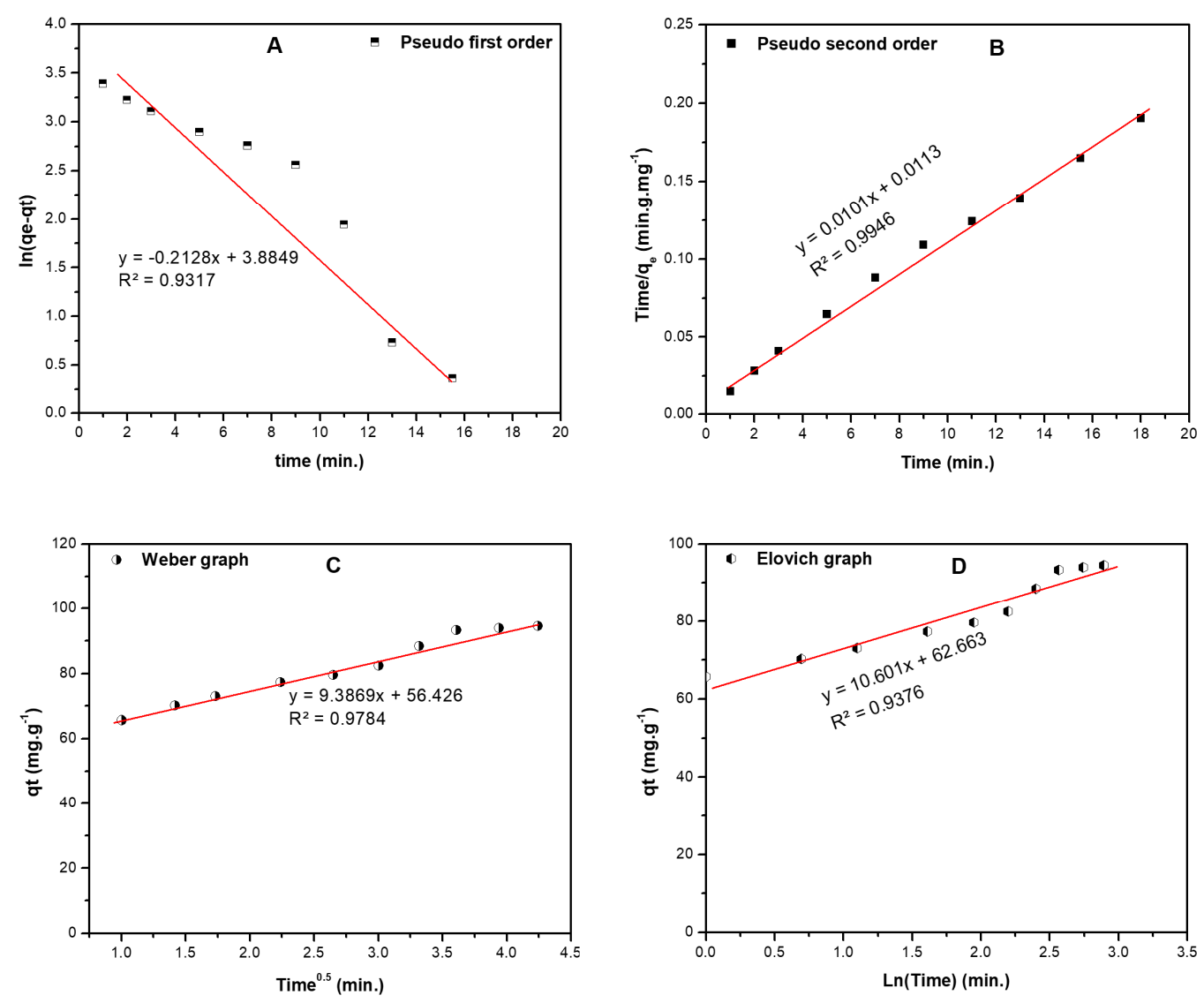

Figure 9. Kinetic models for the adsorption of BF dye on raw pistachio nutshells including: (A) first order, (B) second order, (C) Elovich, and (D) intra-particle diffusion (Weber-Morris (W-M)) curve. The following conditions were employed to obtain the listed models: DC: 200ppm, AD: $1.500 \pm 0.005 \mathrm{~g}$, pH: $12.00 \pm 0.20$, and ST: 1-18 min.). 
Table 9. The kinetics study results corresponding to Figure 9.

\begin{tabular}{|c|c|c|}
\hline Models & Parameter & Value \\
\hline $\begin{array}{l}\text { Pseudo-first order (PFO) } \\
\ln (q e-q t)=\ln (q e)-k_{1} t\end{array}$ & $\begin{array}{c}K_{1}\left(\mathrm{~min}^{-1}\right) \\
q_{e}(\mathrm{mg} / \mathrm{g}) \\
\mathrm{R}^{2}\end{array}$ & $\begin{array}{l}0.213 \\
48.66 \\
0.932\end{array}$ \\
\hline $\begin{array}{l}\quad \text { Pseudo-second order (PSO) } \\
\qquad \frac{t}{q e}=\frac{1}{k_{2} q_{e}^{2}}+\frac{1}{q_{e}} \mathrm{t} \\
\text { Where } \mathrm{K}_{2} \text { is rate constant }\left(\mathrm{g} \cdot \mathrm{mg}^{-1} \cdot \mathrm{min}^{-1}\right)\end{array}$ & $\begin{array}{c}\mathrm{K}_{2} \\
\left(\mathrm{~g} \cdot \mathrm{mg}^{-1} \cdot \mathrm{min}^{-1}\right) \\
q_{e}(\mathrm{mg} / \mathrm{g}) \\
\mathrm{R}^{2}\end{array}$ & $\begin{array}{c}9.03 \times 10^{-3} \\
99.01 \\
0.995\end{array}$ \\
\hline $\begin{array}{l}\text { Elovich equation is } q_{t}=\beta \ln (\alpha \beta)+\beta \ln (t) \text { is used to predict the sorption mechanism, } \\
\text { where } q_{t} \text { is adsorbed quantity at time t; while } \alpha \text { and } \beta \text { are initial sorption concentration } \\
\text { rate }\left(\mathrm{mg}^{-1} \mathrm{~g}^{-1} \cdot \mathrm{min}^{-1}\right) \text {, and desorption constant }(\mathrm{g} / \mathrm{mg}) \text {, respectively. }\end{array}$ & $\begin{array}{c}\alpha \\
B \\
R^{2}\end{array}$ & $\begin{array}{l}34.82 \\
10.60 \\
0.938\end{array}$ \\
\hline $\begin{array}{l}\text { Weber-Morris intraparticle diffusion model is used to study the formed layers around the } \\
\text { adsorbent and rate-controlling step, which is expressed as } q_{t}=K_{I} t^{0.5}+C \text {, where } K_{\mathrm{I}} \text { is } \\
\text { intraparticle diffusion rate constant }\left(\mathrm{mg}^{-1} \mathrm{~g}^{-1} \cdot \mathrm{min}^{-0.5}\right) \text {, and } \mathrm{C} \text { is boundary thickness effect. }\end{array}$ & $\begin{array}{l}\mathrm{K}_{\mathrm{I}} \\
\mathrm{C} \\
\mathrm{R}^{2}\end{array}$ & $\begin{array}{l}9.39 \\
56.43 \\
0.978\end{array}$ \\
\hline
\end{tabular}

The reaction rate of the adsorption can be given as rate $=-k[B F]^{n}[R P N S]^{m}$, while the adsorbent is added in excess so the reaction rate can be written as rate $=-k[B F]^{n}$, and $n=2$.

From the W-M intraparticle diffusion model, Figure 9 C, the diffusion rate is low and the boundary layer $\left(56.43 \mathrm{mg} / \mathrm{g}\right.$ ) is close to the $q_{\max }$ calculated by Langmuir isotherm, so the mechanism is controlled by adsorption rate. According to the Elovich model shown in Figure 9D, the $\mathrm{R}^{2}$ values is low $(0.938)$ compared to the other models. The initial sorption rate is three times higher than the desorption rate; therefore, the adsorption capacity could be enhanced by increasing the stirring time (ST), an issue that is confirmed by the output of DSD, Equation (4).

\section{Conclusions}

Pistachio nutshells leaves could be re-utilized as an adsorbent for basic fuchsin from contaminated water samples. Seven adsorbents could be developed from PNS. Raw pistachio nut shells proved to be a more efficient adsorbent compared to thermally treated samples (PNS250-500). Screening and optimization of the variables impacting the adsorption process was done using a smart approach; definitive screening design. A single response, adsorption capacity $\left(q_{e}\right)$ was measured in terms of four variables; $\mathrm{pH}$, adsorbent dose ' $\mathrm{AD}^{\prime}$ ', dye concentration ' $\mathrm{DC}^{\prime}$ ', and stirring time 'ST'. The target was set to maximize the response. A mathematical model was therefore developed to predict the adsorption capacity. As per the regression model, increasing the concentration of BF enhanced the adsorption capacity, in contrary to the dose of the adsorbent; RPNS.

Results show that the RPNS is formed mainly of hemicellulose, cellulose, and lignin with different percentages as shown by TGA and FT-IR. The thermal treatment of the samples leads to an improvement in the surface area as shown by BET and SEM analyses.

Equilibrium studies reveal that the adsorption is physisorption with adsorption energy of $7.4 \mathrm{~kJ}$, and a maximum capacity of $58.8 \mathrm{mg} / \mathrm{g}$ as indicated by Dubinin-Radushkevich and Langmuir isotherms. The kinetics study shows that the adsorption is pseudo-second-order with respect to BF, which is controlled by adsorption rate with boundary layer of $56.4 \mathrm{mg} / \mathrm{g}$. Finally, the initial sorption rate is almost three times the desorption rate.

Author Contributions: Conceptualization, M.E.-A.; Data curation, M.E.-A., A.A.; Formal analysis, M.E.-A., A.S.E.-S. and A.A.I.; Funding acquisition, M.E.-A.; Investigation, M.E.-A., A.A.; Methodology, M.E.-A.; Project administration, M.E.-A.; Resources, A.A.I.; Software, M.E.-A.; Supervision, M.E.-A.; Validation, M.E.-A., A.S.E.-S.; Visualization, M.E.-A.; Writing—original draft, M.E.-A.; Writing—review \& editing, M.E.-A., A.S.E.-S. and A.A.I.

Funding: This work was made possible by Qatar University Internal Student Grant [QUST-2-CAS-2019-18] from Qatar University. The statements made herein are solely the responsibility of the authors. The publication of this article was funded by the Qatar National Library.

Acknowledgments: The project members would like to extend their special thanks to the Central Lab Unit (CLU) at the Qatar University. 
Conflicts of Interest: The authors declare no conflict of interest.

\section{References}

1. Owa, F.D. Water Pollution: Sources, effects, control and management. Med. J. Soci. Sci. 2013, 4, 65-68. [CrossRef]

2. Noroozi, B.; Sorial, G.A. Applicable models for multi-component adsorption of dyes: A review. J. Environ. Sci. 2013, 25, 419-429. [CrossRef]

3. Forgacs, E.; Cserháti, T.; Oros, G. Removal of synthetic dyes from wastewaters: A review. Environ. Int. 2004, 30, 953-971. [CrossRef]

4. Banat, I.M.; Nigam, P.; Singh, D.; Marchant, R. Microbial decolorization of textile-dyecontaining effluents: A review. Bioresour. Technol. 1996, 58, 217-227. [CrossRef]

5. Robinson, T.; McMullan, G.; Marchant, R.; Nigam, P. Remediation of dyes in textile effluent: A critical review on current treatment technologies with a proposed alternative. Bioresour. Technol. 2001, 77, 247-255. [CrossRef]

6. Horobin, R.W.; Kiernan, J.A. Conn's Biological Stains, 10th ed.; BIOS: Oxford, UK, 2002; pp. $184-191$.

7. Clark, G. Staining Procedures Used by the Biological Stain Commission, 3rd ed.; Williams \& Wilkins: Baltimore, MD, USA, 1973; pp. 252-254.

8. Fisher, A.A. Irritant and toxic reactions to phenol in topical medications. Cutis 1980, 26, 363-364.

9. Littlefield, N.A.; Blackwell, B.N.; Hewitt, C.C.; Gaylor, D.W. Chronic toxicity and carcinogenicity studies of gentian violet in mice. Toxicol. Sci. 1985, 5, 902-912. [CrossRef]

10. Gupta, V.K.; Mittal, A.; Gajbe, V.; Mittal, J. Adsorption of basic fuchsin using waste materials-bottom ash and deoiled soya — as adsorbents. J. Colloid Interface Sci. 2008, 319, 30-39. [CrossRef]

11. El Haddad, M. Removal of Basic Fuchsin dye from water using mussel shell biomass waste as an adsorbent: Equilibrium, kinetics, and thermodynamics. J. Taibah Univ. Sci. 2016, 10, 664-674. [CrossRef]

12. Bhole, B.D.; Ganguly, B.; Madhuram, A.; Deshpande, D.; Joshi, J. Biosorption of methyl violet, basic fuchsin et their mixture using dead fungal biomass. Curr. Sci. 2004, 86, 1641-1645.

13. An, S.Y.; Min, S.K.; Cha, I.H.; Choi, Y.L.; Cho, Y.S.; Kim, C.H.; Lee, Y.C. Decolorization of triphenylmethane and azo dyes by Citrobacter sp. Biotechnol. Lett. 2002, 24, 1037-1040. [CrossRef]

14. Ramírez-Montoya, L.A.; Hernández-Montoya, V.; Montes-Morán, M.A. Optimizing the preparation of carbonaceous adsorbents for the selective removal of textile dyes by using Taguchi methodology. J. Anal. Appl. Pyrolysis. 2014, 109, 9-20. [CrossRef]

15. Gómez, V.; Larrechi, M.S.; Callao, M.P. Kinetic and adsorption study of acid dye removal using activated carbon. Chemosphere 2007, 69, 1151-1158. [CrossRef]

16. Gupta, V.K. Application of low-cost adsorbents for dye removal: A review. J. Environ. Manag. 2009, 90, 2313-2342. [CrossRef]

17. Duman, O.; Tunc, S.; Polat, T.G. Adsorptive removal of triarylmethane dye (Basic Red 9) from aqueous solution by sepiolite as effective and low-cost adsorbent. Microporous Mesoporous Mater. 2015, 210, 176-184. [CrossRef]

18. Nayak, A.K.; Pal, A. Green and efficient biosorptive removal of methylene blue by Abelmoschus esculentus seed: Process optimization and multi-variate modelling. J. Environ. Manag. 2017, 200, 145-159. [CrossRef]

19. El-Azazy, M.; El-Shafie, A.S.; Issa, A.A.; Al-Sulaiti, M.; Al-Yafie, J.; Shomar, B.; Al-Saad, K. Potato peels as an adsorbent for heavy metals from aqueous solutions: Eco-structuring of a green adsorbent operating Plackett-Burman design. J. Chem. 2019, 2019, 1-14. [CrossRef]

20. El-Azazy, M.; Kalla, R.N.; Issa, A.A.; Al-Sulaiti, M.; El-Shafie, A.S.; Shomar, B.; Al-Saad, K. Pomegranate peels as versatile adsorbents for water purification: Application of Box-Behnken design as a methodological optimization approach. Environ. Prog. Sustain. Energy 2019, 38, 1-12. [CrossRef]

21. Al-Saad, K.; El-Azazy, M.; Issa, A.A.; Al-Yafei, A.; El-Shafie, A.S.; Al-Sulaiti, M.; Shomar, B. Recycling of date pits into a green adsorbent for removal of heavy metals: A fractional factorial design-based approach. Front. Chem. 2019, 7, 1-16. [CrossRef]

22. Yildiz, S. Kinetic and isotherm analysis of $\mathrm{Cu}$ (II) adsorption onto almond shell (Prunus dulcis). Ecol. Chem. Eng. S 2017, 24, 87-106.

23. Kłos, A. Determination of sorption properties of heavy metals in various biosorbents. Ecol. Chem. Eng. S 2018, 25, 201-216. [CrossRef] 
24. Makuchowska-Fryc, J. Use of the eggshells in removing heavy metals from wastewater-The Process Kinetics and Efficiency. Ecol. Chem. Eng. S 2019, 26, 165-174.

25. Tsang, D.C.W.; Hu, J.; Lui, M.Y.; Zang, W.; Lai, K.C.K.; Lo, I.M.C. Activated carbon produced from waste wood pallets: Adsorption of three classes of dyes. Water Air Soil Pollut. 2007, 184, 141-155. [CrossRef]

26. AL-Saghir, M.G.; Porter, D.M. Taxonomic revision of the genus Pistacia L. (Anacardiaceae). Am. J. Plant Sci. 2012, 3, 12-32. [CrossRef]

27. UN Food and Agriculture Organization, Corporate Statistical Database (FAOSTAT). Pistachio Production in 2017, Crops/Regions/World List/Production Quantity (Pick Lists). 2017. Available online: http://www.fao. org/faostat/en/\#data/QC (accessed on 9 October 2019).

28. SOPIB. Pistachios, Facts, Figures, Fertilizer Research. 2010. Available online: http://www.sopib.com/ 20100309186/news/news/pistachios-facts-figures-fertlizer-research.html/ (accessed on 9 October 2019).

29. El-Shafie, A.S.; Khashan, A.W.; Hussein, Y.H.A.; El-Azazy, M.S. Application of a definitive screening design for the synthesis of a charge-transfer complex of sparfloxacin with tetracyanoethylene: Spectroscopic, thermodynamic, kinetics, and DFT computational studies. RSC Adv. 2019, 9, 24722-24732. [CrossRef]

30. Deniz, F.; Kepekci, R.A. Dye biosorption onto pistachio by-product: A green environmental engineering approach. J. Mol. Liq. 2016, 219, 194-200. [CrossRef]

31. Moussavi, G.; Barikbin, B. Biosorption of Chromium(VI) from industrial wastewater onto pistachio hull waste biomass. Chem. Eng. J. 2010, 162, 893-900. [CrossRef]

32. Moussavi, G.; Barikbin, B. The removal of cationic dyes from aqueous solutions by adsorption onto pistachio hull waste. Chem. Eng. Res. Des. 2011, 89, 2182-2189. [CrossRef]

33. Siddiqui, S.H.; Ahmad, R. Pistachio Shell Carbon (PSC)-an agricultural adsorbent for the removal of $\mathrm{Pb}$ (II) from aqueous solution. Groundw. Sustain. Dev. 2017, 4, 42-48. [CrossRef]

34. Foo, K.Y.; Hameed, B.H. Preparation and characterization of activated carbon from pistachio nut shells via microwave-induced chemical activation. Bioresour. Technol. 2011, 35, 3257-3261. [CrossRef]

35. Jones, B.; Nachtsheim, C.J. A Class of Three-Level Designs for Definitive Screening in the Presence of Second-Order Effects. J. Qual. Technol. 2011, 43, 1-15. [CrossRef]

36. Jones, B.; Nachtsheim, C.J. Definitive Screening Designs with Added Two-Level Categorical Factors. J. Qual. Technol. 2013, 45, 121-129. [CrossRef]

37. Zhang, C.; Chen, W.; Xian, J.; Fu, D. Application of a novel definitive screening design to in situ chemical oxidation of acid orange-II dye by a $\mathrm{Co}^{2+} / \mathrm{PMS}$ system. RSC Adv. 2018, 8, 3934-3940. [CrossRef]

38. Box, G.E.P.; Cox, D.R. An Analysis of Transformations. J. R. Stat. Soc. Ser. B 1964, 26, 211-252. [CrossRef]

39. Antony, J. Design of Experiments for Engineers and Scientists, 1st ed.; Antony, J., Ed.; Elsevier: Amsterdam, The Netherlands, 2003; pp. 6-16.

40. Bruns, R.E.; Scarminio, I.S.; Neto, B.B. Statistical Design-Chemometrics, 1st ed.; Elsevier: Amsterdam, The Netherlands, 2006; Volume 25.

41. Elazazy, M.S. Factorial Design and Machine Learning Strategies: Impacts on Pharmaceutical Analysis. In Spectroscopic Analyses-Developments and Applications; Sharmin, E., Zafar, F., Eds.; IntechOpen: London, UK, 2017; Chapter 11; pp. 213-230.

42. Yang, H.; Yan, R.; Chen, H.; Lee, D.H.; Zheng, C. Characteristics of hemicellulose, cellulose and lignin pyrolysis. Fuel 2007, 86, 1781-1788. [CrossRef]

43. Tounsadi, H.; Khalidi, A.; Abdennouri, M.; Barka, N. Biosorption potential of Diplotaxis harra and Glebionis coronaria L. biomasses for the removal of $\mathrm{Cd}(\mathrm{II})$ and $\mathrm{Co}(\mathrm{II})$ from aqueous solutions. J. Environ. Chem. Eng. 2015, 3, 822-830. [CrossRef]

44. Sarma, G.K.; Khan, A.; El-Toni, A.M.; Rashid, M.H. Shape-tunable CuO-Nd(OH) nanocomposites with excellent adsorption capacity in organic dye removal and regeneration of spent adsorbent to reduce secondary waste. J. Hazard. Mater. 2019, 380, 1-10. [CrossRef]

45. Sun, B.; Yuan, Y.; Li, H.; Li, X.; Zhang, C.; Guo, F.; Liu, X.; Wang, K.; Zhao, X.S. Waste-cellulose-derived porous carbon adsorbents for methyl orange removal. Chem. Eng. J. 2019, 371, 55-63. [CrossRef]

(C) 2019 by the authors. Licensee MDPI, Basel, Switzerland. This article is an open access article distributed under the terms and conditions of the Creative Commons Attribution (CC BY) license (http://creativecommons.org/licenses/by/4.0/). 